\title{
ESTIMATING EFFECTS OF THE DECISION SUPPORT SYSTEM ON EDUCATIONAL AGENTS WITH SIMULATIONS
}

\author{
Ajay Kulkarni \\ Michael Eagle \\ Department of Computational and Data Sciences \\ George Mason University \\ 4400 University Dr. \\ Fairfax, VA, USA \\ \{akulkar8, meagle\}@gmu.edu
}

\begin{abstract}
This paper presents the simulated results of four different scenarios from an ABM to understand the effect of utilization of Alert and Recommender systems on graduation rate. Academic advising help students to enhance their academic performance, and it is also one of the critical aspects of judging institutional effectiveness. For evaluating the effectiveness, college graduation rates are calculated for every scenario, and then they are compared with the baseline scenario. This objective is achieved by using details of SAT scores and core courses of the Department of Physics and Astronomy at a large public university. The prime focus of the paper is to model the impact of the system, which, in reality, helps to save time and cost. The preliminary results show that the Alert and Recommender system could have a positive impact on graduation rates.
\end{abstract}

Keywords: Alert system, Recommender system, College graduation rate, Power analysis, T-test

\section{INTRODUCTION}

Agent-based modeling (ABM) is a simulation technique that contains a collection of autonomous decisionmaking agents (Bonabeau 2002). It is a bottom-up modeling approach in which the behavior of the systems is modeled based on individual-level interactions ( $\mathrm{Gu}$ and Blackmore 2015). Every agent in an ABM is an entity having certain specific attributes and interacts with the environment based on the provided rules (Macal and North 2005). (Triulzi, Scholz, and Pyka 2011) stated that the true dynamics in universities are difficult to model with conventional quantitative analysis. Thus, ABM is one of the approaches that can be used to model the true dynamics. ABMs typically consist of three elements - agents, their relationships $\&$ interactions, and the environment (Macal and North 2005). This paper brings forth results from ABM simulations to understand the effect of using Alert and Recommender systems to improve the graduation rates. The paper attempts to show the importance of simulations while designing the system. In this model, students act as agents who interact with advisors in an educational institution.

College graduation plays an essential role in students' careers as well as for the institutions. Students with a college degree can earn six times as much as college dropouts (Murphy and Welch 1993). For educational institutions, it is used as a measure of institutional effectiveness (Murtaugh, Burns, and Schuster 


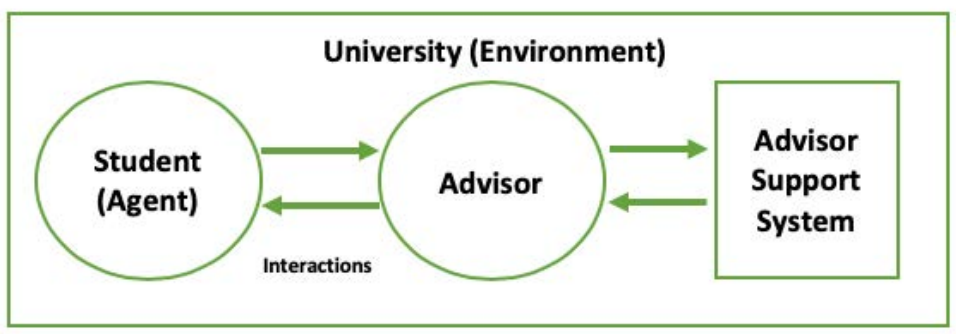

Figure 1: Conceptual diagram of the developed ABM.

1999). The second most crucial evaluation criterion for institutional effectiveness is academic advising (Kelley and Lynch 1991). Academic advisors work as a bridge between educational institutions and students. The advisors who are well organized, on time, and prepared for meetings are highly effective (Kelley and Lynch 1991). Based on the literature (Kelley and Lynch 1991), (Winston Jr and Sandor 1984), (Smith and Allen 2006) the five responsibilities of the advisors are - guiding students for selecting their majors and minors, helping students to choose relevant and useful courses, detecting and advising students whose performances are declining, providing valuable academic resources, and informing students on sources of help and activities offered through Student Affairs Division. Therefore, academic advisors play a vital role as a guide to undergraduate students. Academic advisors also teach, conduct research, write grants, and advise graduate students. With that in mind, it makes academic advisors less efficient due to their heavy workload. Thus, the Advisor Support System is proposed to lessen their workload and increase their efficiency. This paper presents simulated results from the features of the proposed system on four different scenarios and explains how it affects college graduation rates.

The organization of the paper is as follows: Section 2 presents the literature for usefulness of SAT scores for predicting First Year GPA (FYGPA), and the impact of academic advising on student's academic performance; Section 3 describes the data being used for the simulations; Section 4 explains the design and conditions used in agent-based model; Section 5 discusses simulated scenarios and initial conditions; Section 6 describes the experimental results; Section 7 concludes the findings, and explains the future steps.

\section{BACKGROUND AND RELATED WORK}

This section is divided into two subsections. The first subsection explains the background, which reflects the importance of SAT scores for predicting FYGPA, and the impact of academic advising on students' performance. The second subsection lists the related work in the domain of applications of ABMs in Higher Education (HE).

\subsection{Background}

The purpose of the Scholastic Assessment Test (SAT) is to measure a student's potential for academic success in college (Kobrin, Patterson, Shaw, Mattern, and Barbuti 2008). Based on approximately 3000 studies in 2001, Hezlett et al. (Hezlett, Kuncel, Vey, Ahart, Ones, Campbell, and Camara 2001) noted that SAT scores are a valid predictor of FYGPA. Later in 2006, CollegeBoard (Fishman and Pasanella 1960) analyzed data from 30 colleges by using a sample of 34,000 students who entered college in the fall of 1995 . The data was analyzed using correlation analysis and concluded that across most of the demographics, the SAT score was an equally effective or slightly better predictor than High School GPA (HSGPA) for predicting FYGPA. In another study, (Kobrin and Michel 2006) single and multiple correlations are used to understand the relationship of SAT and High School GPA with FYGPA. After calculations, it was noted that 
SAT and High school GPA are significant predictors for predicting student's success. Further, it was also stated that the writing section of the SAT has the highest correlation with FYGPA.

Academic advising positively affects student retention (Baldridge, Kemerer, Green, et al. 1982), (Habley 1981), (Habley and McClanahan 2004), and it helps students in making decisions, identifying resources, solving problems, as well as for setting personal, professional and/or academic goals (Crookston 2009) (O’Banion 1994), (Swecker, Fifolt, and Searby 2013), (Winston, Ender, and Miller 1982). A study conducted by Swecker et al. (Swecker, Fifolt, and Searby 2013) based on 363 first-year first-generation students concluded that every meeting with an academic advisor increases $13 \%$ chance of student retention. Kirk-Kuwaye et al. (Kirk-Kuwaye and Nishida 2001) conducted a study to understand the effect of low and high advisor involvement on the academic performance of probated students. For this experiment, low and high involvement groups were created. For high involvement group, academic advisors held mandatory meetings, made an agreement to use resources, provided materials/web sites on studying strategy, made reminder phone calls, and provided assignments along with a letter of notification. On the other hand, academic advisors in the low involvement group provided only letters of notifications. The authors concluded that there was a high semester mean GPA for students from high involvement group as compared to the low involvement group. It is also noted that students from high involvement group never felt annoyed by the involvement of the institution at a higher level. Based on the survey of 611 students (Young-Jones, Burt, Dixon, and Hawthorne 2013), it was found that that meeting with an advisor at least one time during a semester contributed to the multiple factors affecting students' success. Felly Chiteng Kot (Kot 2014) conducted a study to understand the impact of centralized advising on the performance of first-year students and its effect on the enrollment for the second year. Based on the conducted study, the author noted that there was a net gain of $31 \%$ in first-term GPA, $22 \%$ on average in second-term GPA and $25 \%$ on average in Cumulative GPA at the end of the first academic year for the students who utilized the centralized advising service. This study also showed that students who used centralized advising were more likely to return in the second year.

\subsection{Related work}

X. Gu and K.L. Blackmore (Gu and Blackmore 2015) conducted a systematic review of agent-based modeling and simulation in the domain of higher education. The authors identified six categories based on different parameters such as agents of each model, the relationship between agents, users of the model, and the purpose of the model. These six identified categories were: university system, university collaboration, academic activities, application \& enrolment, student performance, and teaching \& learning. Under student performance, authors found only four articles that were based on online peer support (De Bakker, Van Bruggen, Jochems, and Sloep 2011), students' grades, and graduate employment (Cai 2013),(Mori and Kurahashi 2011). (Gu and Blackmore 2015) also notes that an ABM developed by Cyprian Wejnert (2006) for understating the grade inflation uses three macro-level processes - student effort adjustment, grading on the curve, and voting with feet along with their interactions. Based on the simulated results, Cyprian Wejnert concluded that grade inflation is a naturally occurring phenomenon.

\section{DATA AND COURSE DEPENDENCY MAP}

The model is designed for the Department of Physics and Astronomy at a large public university. The data (core courses and prerequisites) for the experiments are taken from the university's advising webpage. A detailed list of courses and prerequisites used in the model is given in table 1. As per table 1, certain courses will need one/two/three/four prerequisites. The notable observation from the degree worksheet is - PHYS 251 is not present as a core course, but it is a prerequisite for PHYS 410. Thus, a change is made in the degree worksheet by adding PHYS 251 as a mandatory core course in the fourth semester. The literature 
review points out that SAT scores are one of the critical predictors of the student's performance in the first semester. Thus, the average SAT scores published for Mathematics, Critical Reading, and Writing sections from the Business Insider (Business insider 2014) are used for simulating the performance of students in the first year. Based on the data, course dependency maps are created for every year, which are further used for simulating different scenarios. An example of a dependency map for the third year is shown in figure 2 .

Table 1: Core courses and prerequisites for the Department of Physics and Astronomy.

\begin{tabular}{|c|c|c|}
\hline Semester & Core courses & Prerequisites \\
\hline \multirow{3}{*}{ Fall (Year 1) } & MATH 113(Analytic Geometry and Calculus) & \\
\hline & PHYS 122/123 (Inside Relativity/ Inside the Quantum World) & \\
\hline & ENGH 101 (Composition) & \\
\hline \multirow{4}{*}{ Spring (Year 1) } & MATH 114 (Analytic Geometry and Calculus II) & MATH 113 \\
\hline & ASTR 124 (Introduction to Observational Astronomy) & \\
\hline & PHYS 160 (University Physics I) & MATH 114 \\
\hline & PHYS 161 (University Physics I Laboratory) & PHYS 160 \\
\hline \multirow{4}{*}{ Fall (Year 2) } & MATH 213 (Analytic Geometry and Calculus III) & MATH 114 \\
\hline & PHYS 260 (University Physics II) & PHYS 160, MATH 213 \\
\hline & PHYS 261 (University Physics II Laboratory) & PHYS 161, PHYS 260 \\
\hline & PHYS 251 (Introduction to Computer Techniques in Physics) & PHYS 160 \\
\hline \multirow{5}{*}{ Spring (Year 2) } & MATH 214 (Analytic Geometry and Calculus II) & MATH 213 \\
\hline & PHYS 307 (Thermal Physics) & PHYS 260 \\
\hline & PHYS 308 (University Physics I) & PHYS 260 \\
\hline & ASTR 210 (Introduction to Astrophysics) & PHYS 160 \\
\hline & Elective - PHYS 265 (Intermediate University Physics Laboratory) & PHYS 251, PHYS 260 \\
\hline \multirow{5}{*}{ Fall (Year 3) } & PHYS 301 (Analytical Methods of Physics) & MATH 214 \\
\hline & PHYS 303 (Classical Mechanics) & PHYS 260, PHYS 301 \\
\hline & PHYS 305 (Electromagnetic Theory) & PHYS 260, PHYS 301 \\
\hline & PHYS 311 (Instrumentation) & PHYS 251, PHYS 261 \\
\hline & ENGH 302 (Advanced Composition) & ENGH 101 \\
\hline \multirow{3}{*}{ Spring (Year 3) } & PHYS 306 (Wave Motion and Electromagnetic Radiation) & PHYS 305 \\
\hline & PHYS 312 (Waves and Optics) & PHYS 251, PHYS 261 \\
\hline & PHYS 402 (Introduction to Quantum Mechanics and Atomic Physics) & PHYS 303, PHYS 305, PHYS 308 \\
\hline \multirow{5}{*}{ Fall (Year 4) } & PHYS 403 (Quantum Mechanics II) & PHYS 402 \\
\hline & PHYS 407 (Senior Laboratory in Modern Physics) & PHYS 251, PHYS 311, PHYS 312, PHYS 402 \\
\hline & PHYS 408/409 (Senior Research/ Physics Internship) & PHYS 251, PHYS 301, PHYS 303, PHYS 305 \\
\hline & PHYS 410 (Computational Physics Capstone) & PHYS 303, PHYS 305, PHYS 251, PHYS 265 \\
\hline & PHYS 416 (Special Topics in Undergraduate Physics) & \\
\hline \multirow{2}{*}{ Spring (Year 4) } & PHYS 412 (Solid State Physics and Applications) & PHYS 402/502 \\
\hline & PHYS 428 (Relativity) & PHYS 303, PHYS 305 \\
\hline
\end{tabular}

\section{AGENT-BASED MODEL DESIGN}

In this $\mathrm{ABM}$, five unique cases are designed using particular rules and conditions. These cases are developed by considering all the elements such as students' SAT scores, their overall performance in the previous semester(s), and course prerequisites. SAT scores for all the sections and quality points were generated using the normal distribution. The detailed discussions of all the cases are as follows.

\section{Case 1: First semester}

In the first semester, rules are created by considering individual section scores of the SAT. The model is developed for the Department of Physics and Astronomy. Thus, while designing rules, higher importance is given to the Mathematics section as compared to Critical Reading and Writing sections. For every simulation, the highest scores of every section are recorded and used for comparison with other agents' scores in the respective simulation. After comparing with the highest score, quality points are allocated based on the defined conditions. 


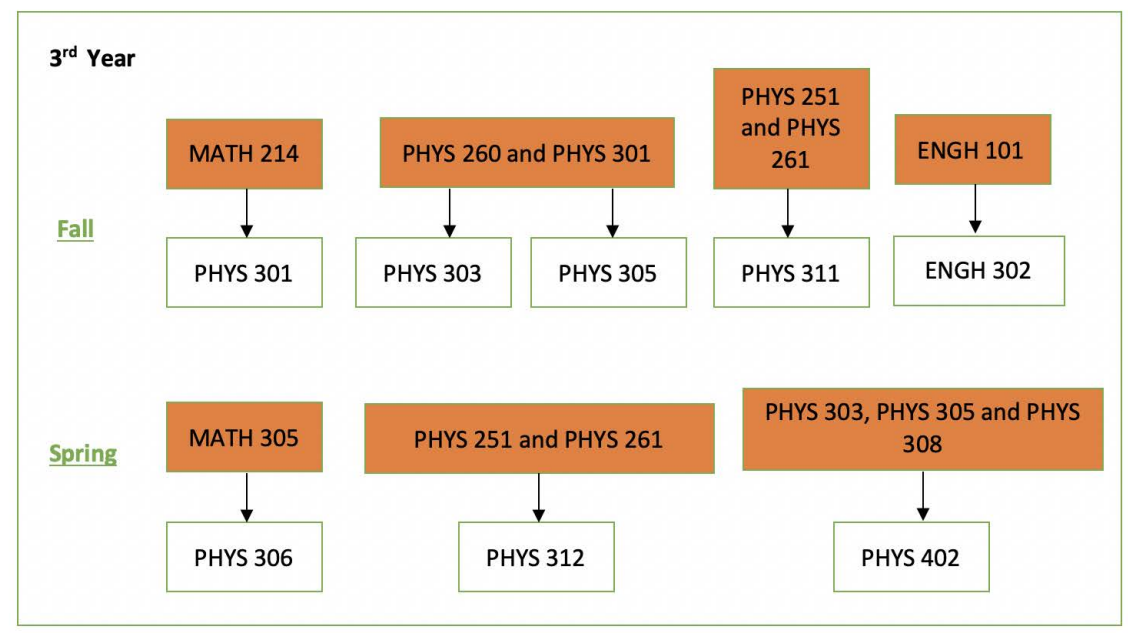

Figure 2: Course dependency map for third year.

For example, the first condition is if an agent's SAT score in every section is greater than or equal to the highest score - 5; then, an agent will get quality points between 3.67 and 4 . In this way, the quality points are divided into five categories ( 3.67 to 4,3 to $3.67,2.67$ to 3,2 to 3 and 0 to 2), and four unique conditions are developed for every situation. An agent will get grade points between 0 and 2 if the agent is unable to fulfill one of the provided conditions.

\section{Case 2: One prerequisite}

This case explains the rules created for the courses which require only one prerequisite. The quality points for a core course with a prerequisite is calculated by considering an agent's performance in that particular prerequisite. For example, in third-semester MATH 114 is a prerequisite for MATH 213, and thus the performance of an agent in MATH 114 is considered for predicting the quality points for MATH 213 . Five unique conditions are developed for this case and details are as follows.

- If an agent's quality points in the prerequisite are greater than or equal to 3.67 , then the agent will receive quality points between 3.67 and 4 .

- If an agent's quality points in the prerequisite are greater than 3.33 but less than 3.67 , then the agent will earn quality points between 3.33 to 3.67 .

- If an agent's quality points in the prerequisite are greater than 3 but less than 3.33 , then the agent will receive quality points between 2.67 and 3.33 .

- If an agent's quality points in the prerequisite are greater than 2 but less than 3 , then an agent will receive quality points between 2 and 3 .

- If all the above conditions are not satisfied, then an agent will get quality points between 0 and 2 .

\section{Case 3: Two prerequisites}

In this scenario, quality points are predicted for a course based on two required prerequisites. For example, in the fifth semester, it can be observed that PHYS 311 requires two prerequisites (PHYS 251 and PHYS 261). Thus, an agent's performance in PHYS 311 is predicted based on the performance of PHYS 251 and PHYS 261. The unique conditions developed for this case are as follows 
- If an agent's grade points are greater than or equal to 3.67 in both the prerequisites, then an agent will receive quality points between 3.67 and 4 .

- If quality points for two core courses are between 3 and 3.33 or if quality points are greater than or equal to 3.33 in one of the prerequisites and for the other prerequisite, if the quality points are between 3 and 3.33, then a student will receive quality points between 3.33 and 3.67.

- The logic explained in the above condition extended for predicting the grade points in the third, fourth, and fifth conditions. In the third condition, the grade points are predicted between 3 and 3.33. In the fourth condition, grade points are predicted in the range of 2.67 and 3. Finally, in the fifth condition, grade points are predicted in the range of 2 and 2.67 .

- If none of these conditions are satisfied, then an agent will get quality points between 0 and 2 .

\section{Cases 4 and 5: Three and four prerequisites}

The conditions used in case 3 are extended for case 4 and case 5. In the sixth semester, the core course PHYS 402 has three prerequisites - PHYS 303, PHYS 305, and PHYS 308. Thus, the grade points of all three prerequisites are used for calculating the agent's quality points in PHYS 402. Similarly, in the seventh semester, an example of a course (PHYS 407) can be seen. In this case, grade points of all four prerequisites are considered for calculating the agent's quality points in PHYS 407.

\section{SIMULATED SCENARIOS AND INITIAL CONDITIONS}

The previous section explained the details of the rules that power the agent-based model. This section will shed light on the simulated scenarios in the model. In this model, students are considered as agents, and the environment is the university/college. These agents will interact with their advisors based on the designed rules and conditions. Further, every iteration simulates an agent's (i.e., student) college journey. The model will start from the first year of college (Fall semester), and it will stop at the end of the fourth year (Spring semester). One of the assumptions made in the model is that the agents will start their college journey from the Fall semester, and it will end in the Spring semester (fourth year).

Every agent is associated with 56 attributes, which includes their id, SAT scores (Mathematics, Critical Reading, and Writing), core courses (details in table 1), semester wise GPA, final GPA, and a flag variable - "fail" for understating count of students who failed. The difference between any two consecutive grades at a large public university used for these experiments is 0.33 . For example, the difference between grades A (quality points $=4$ ) and A- (quality points $=3.67$ ) is 0.33 . Thus, the value 0.33 is selected in scenario 2 (alert system) for comparison. Further, B- grade is represented by 2.67 quality points, and 2.33 quality points represent $\mathrm{C}+$ grade. One of the requirements of the core courses is to earn at least a " $\mathrm{C}$ " grade. Thus, the students whose previous semester GPA is less than 2.5 have a higher probability of failing in the next semester. Therefore, it is more important to target those students. This situation is replicated using scenario 2. The details of the simulated four scenarios in the model are given below.

Scenario 1 - The advisor does not initiate contact with the students; instead, the students will contact their advisor for a meeting.

Scenario 2 - Advisor will contact students and ask them to meet if their overall GPA from the previous semester is less than 2.5, or the difference between two consecutive semesters is greater than or equal to 0.33 .

Scenario 3 - The decision support system will help advisors to be more efficient and provide more information about students. It will give suggestions to advisors for recommending courses that can help students to increase their GPA. It is assumed that at least ten students will improve their performance in every semester. 
Scenario 4 - Combination of scenario 2 and scenario 3.

The outlined scenarios are simulated 100 times using 100 agents for three runs. Scenario 1 is a baseline scenario, and the other scenarios are compared to understand which scenario produces the greatest improvement in the graduation rate. For this comparison, the average change in the graduation rate is used as a metric. For scenarios 2 and 3, the results are simulated to understand how 5\%, 10\%, 15\%, and 20\% performance increase in every semester affects the graduation rate. Scenario 4 is a combination of scenarios 2 and 3. In the first case of scenario 4, it is assumed that there will be a 5\% increase in the performance, and in the second case, it is assumed that there will be a $15 \%$ increase in the performance. For both cases, the performance in scenario 3 is simulated for different values to understand the effect on scenario 4 . The results from these experiments give insight into two crucial aspects - will these scenarios affect graduation rate and if so, by how much?

Table 2: Initial conditions for simulations.

\begin{tabular}{|c|l|c|}
\hline & \multicolumn{1}{|c|}{ Variable } & Value \\
\hline \multirow{4}{*}{ Model parameters } & Number of agents & 100 \\
\cline { 2 - 3 } & Number of simulations & 100 \\
\cline { 2 - 3 } & Number of runs & 3 \\
\hline \multirow{4}{*}{ SAT score parameters } & Average critical reading score & 558 \\
\cline { 2 - 3 } & Standard deviation for critical reading & 10 \\
\cline { 2 - 3 } & Average math score & 585 \\
\cline { 2 - 3 } & Standard deviation for math score & 4 \\
\cline { 2 - 3 } & Average writing score & 540 \\
\cline { 2 - 3 } & Standard deviation for writing score & 10 \\
\hline
\end{tabular}

\section{COMPUTATIONAL EXPERIMENTS AND RESULTS}

\subsection{Results from simulations}

One notable observation which the model depicts is the failure rate is high in the first academic term, and overall, it is the highest at the end of the second year. After the second academic year, there is a relatively less percentage of students failing. Scenario 2 and scenario 4 indicate a significant increase in the graduation rate based on the mean percentage change in the graduation rate. For scenario 2 (table 4), the simulated average in the graduation rate increased by $0.1 \%, 0.59 \%, 0.64 \%$ and $0.71 \%$ for $5 \%, 10 \%, 15 \%$ and $15 \%$ increase in the performance respectively. For scenario 3 (table 4 ), only one case (10\% increase in the performance) shows a decrease in the graduation rate by $0.5 \%$. The results of scenario 4 (table 5 ) show a gradual increase in the graduation rate. It can be observed that case 1 of scenario 4 shows a maximum $0.53 \%$ increase in the graduation rate and a minimum $0.16 \%$ increase in the graduation rate, respectively. Case 2 of scenario 4 reports a maximum $0.73 \%$ increase in the graduation rate and a minimum $0.07 \%$ increase in the graduation rate from simulations.

Table 3: Scenario 1 - The average graduation rate is $61.38 \%$.

\begin{tabular}{|c|c|}
\hline Number of runs & Average graduation rate at the end of 4th year \\
\hline 1 & $60.76 \%$ \\
\hline 2 & $62.29 \%$ \\
\hline 3 & $61.11 \%$ \\
\hline
\end{tabular}


Table 4: In Scenario 2, the overall average graduation rate increases from $0.1 \%$ to $0.70 \%$, and in Scenario 3 , there is an increase in the graduation rate for all cases except when there is a $10 \%$ increase in the performance.

\begin{tabular}{|c|c|c|c|}
\hline Number of runs & \% increase in the performance & \multicolumn{2}{|c|}{ Average graduation rate at the end of 4th year } \\
\hline & & Scenario 2 & Scenario 3 \\
\hline \multirow{4}{*}{1} & $5 \%$ & $61.41 \%$ & $60.87 \%$ \\
\cline { 2 - 4 } & $10 \%$ & $62.74 \%$ & $60.44 \%$ \\
\cline { 2 - 4 } & $15 \%$ & $62.69 \%$ & $62.02 \%$ \\
\hline \multirow{4}{*}{2} & $20 \%$ & $62.43 \%$ & $61.43 \%$ \\
\cline { 2 - 4 } & $5 \%$ & $61.58 \%$ & $61.52 \%$ \\
\cline { 2 - 4 } & $10 \%$ & $61.72 \%$ & $61.87 \%$ \\
\hline \multirow{4}{*}{3} & $15 \%$ & $62.28 \%$ & $64.21 \%$ \\
\cline { 2 - 4 } & $20 \%$ & $62.22 \%$ & $62.62 \%$ \\
\cline { 2 - 4 } & $5 \%$ & $61.46 \%$ & $62.64 \%$ \\
\cline { 2 - 4 } & $10 \%$ & $61.46 \%$ & $60.34 \%$ \\
\hline
\end{tabular}

Table 5: The overall average graduation rate gradually increases from $0.16 \%$ to $0.53 \%$ and $0.07 \%$ to $0.73 \%$ in Case 1 and Case 2 of Scenario 4 respectively.

\begin{tabular}{|c|c|c|}
\hline \% increase in the performance & Mean percentage change in the graduation rate (Scenario 4) \\
\hline & Case 1 & Case 2 \\
\hline $5 \%$ & $0.16 \%$ & $0.07 \%$ \\
\hline $10 \%$ & $0.37 \%$ & $0.31 \%$ \\
\hline $15 \%$ & $0.43 \%$ & $0.43 \%$ \\
\hline $20 \%$ & $0.53 \%$ & $0.73 \%$ \\
\hline
\end{tabular}

\subsection{Power analysis and t-tests}

Power analysis helps to make accurate and reliable conclusions from the statistical tests. For conducting power analysis for paired t-tests, the baseline scenario is compared with all the scenarios. A paired t-test is useful for comparing the before and after effect of treatment on samples. Thus, a paired t-test helps us to understand the statistical significance of the difference in the mean values. For calculating sample sizes using power analysis, three parameters - effect size, significance level, and power of a test are used. The effect sizes are computed for every scenario using Cohen's formula, which requires the difference between the means and pooled standard deviations. Values for the significance level (0.05) and the power of a test (0.80) are kept constant throughout the experiments. The calculated sample sizes, along with the effect sizes for every scenario, are included in table 6 .

The majority of the calculated effects (d) are between 0 to 0.20 , which reflects a small effect. The maximum effect observed for the third case (15\%) of scenario 3, and the smallest effect noted for the second case (5\%) of scenario 4. The results show that scenario 2 (all except 5\%), scenario $3(15 \%, 20 \%$ ), and case 2 of scenario 4 (20\%), need sample sizes less than 500. These results are useful for understanding effect sizes and the requirement of sample sizes to conduct these experiments in real-life.

To confirm the statistical validity of the results, the paired t-tests are performed on 100 samples. In paired t-test, the null hypothesis indicates there is no difference between the two means, i.e., $\mu_{1}=\mu_{2}$ and 
Table 6: Details of effect and sample sizes for all scenarios.

\begin{tabular}{|c|c|c|c|c|c|}
\hline Scenario & Experiments & Mean & Standard deviation & Effect (d) & Sample size \\
\hline 1 & Baseline & $61.39 \%$ & $4.53 \%$ & & \\
\hline \multirow{4}{*}{2} & $5 \%$ & $61.48 \%$ & $4.27 \%$ & 0.02 & 19624.07 \\
\cline { 2 - 6 } & $10 \%$ & $61.97 \%$ & $4.50 \%$ & 0.13 & 466.354 \\
\cline { 2 - 6 } & $15 \%$ & $62.02 \%$ & $4.38 \%$ & 0.14 & 402.377 \\
\cline { 2 - 6 } & $20 \%$ & $62.09 \%$ & $4.57 \%$ & 0.15 & 350.377 \\
\hline \multirow{4}{*}{3} & $5 \%$ & $61.68 \%$ & $4.26 \%$ & 0.07 & 1603.73 \\
\cline { 2 - 6 } & $10 \%$ & $60.88 \%$ & $4.42 \%$ & -0.11 & 650.5895 \\
\cline { 2 - 6 } & $15 \%$ & $62.72 \%$ & $4.59 \%$ & 0.29 & 95.26629 \\
\cline { 2 - 6 } & $20 \%$ & $62.43 \%$ & $4.18 \%$ & 0.24 & 138.198 \\
\cline { 2 - 6 } & $5 \%$ & $61.55 \%$ & $5.14 \%$ & 0.03 & 8722.877 \\
\cline { 2 - 6 } & $10 \%$ & $61.62 \%$ & $4.65 \%$ & 0.05 & 3141.465 \\
\cline { 2 - 6 } & $15 \%$ & $61.82 \%$ & $4.85 \%$ & 0.09 & 970.9176 \\
\hline \multirow{4}{*}{4 (case 2) } & $20 \%$ & $61.92 \%$ & $4.10 \%$ & 0.12 & 546.9836 \\
\cline { 2 - 6 } & $5 \%$ & $61.46 \%$ & $4.99 \%$ & 0.01 & 78390.53 \\
\cline { 2 - 6 } & $10 \%$ & $61.70 \%$ & $4.95 \%$ & 0.07 & 1603.73 \\
\cline { 2 - 6 } & $15 \%$ & $61.82 \%$ & $5.43 \%$ & 0.09 & 970.9176 \\
\hline
\end{tabular}

the alternative hypothesis specifics there is a difference between the means of the two samples, i.e., $\mu_{1} \neq \mu_{2}$. To perform a paired t-test, 100 samples for every scenario are used.

Before performing a paired t-test, the assumption of normality was checked using the Shapiro-Wilk normality test for the differences. In the Shapiro-Wilk normality test, the null hypothesis indicates that the data is normally distributed, and the alternative hypothesis specifies that the data does not fit the normal distribution. The assumption of normality was checked using an alpha level of .05. It was observed that all the variables resulted in p-values greater than .05 . These results indicate that the normality assumption is fulfilled.

After testing the assumption of normality, paired t-tests were conducted with an alpha level of .05 to determine the significance in the differences between the mean graduation rate for different scenarios. Scenario 1 was used as a baseline scenario, and the other scenarios were compared with it to check the significance of the differences in the graduation rate. There was a significant difference in the graduation rate for scenario 1 $(\mathrm{M}=60.76, \mathrm{SD}=6.95)$ and scenario 3 when there was a $15 \%$ increase in the performance $(\mathrm{M}=64.21, \mathrm{SD}=$ $7.77) ; \mathrm{t}(99)=-3.01, \mathrm{p}=.003$. A significant difference is also noted in the graduation rate of scenario $1(\mathrm{M}=$ $60.76, \mathrm{SD}=6.95$ ) and scenario 4 (case 2) when there is a $20 \%$ increase in the performance $(\mathrm{M}=63.64, \mathrm{SD}$ $=7.58) ; \mathrm{t}(99)=-2.98, \mathrm{p}=.003$. Thus, we may say that the graduation rate might increase if we were able to successfully implement the proposed policies for the alert and recommender systems.

\section{CONCLUSION AND NEXT STEPS}

The paper examines the simulated results of the four different scenarios to understand its effect on the college graduation rate. The results were obtained by developing and simulating an ABM based on SAT scores and core courses. The simulated results indicate that there is an increase in the college graduation rate in all the scenarios except for scenario 3 when there is an increase in $10 \%$ in the performance. For scenario 4 (case 1 and case 2) there is a gradual increase in the graduation rate at the end of the fourth year. Further, power analysis was performed to understand the size of the effects and sample sizes needed to prove those effects. The power analysis indicated that the majority of the effects are small effects and the maximum 
effect was observed for scenario 3, when there was a $15 \%$ increase in the performance. It also noted that the majority of scenarios need a sample size higher than 500. For scenario 3 (15\% and 20\%), it might be realistic to perform these experiments in real-life, but for the other scenarios, it will be difficult to prove this in real-life. The small effect sizes also indicate the need for alternative metrics such as the number of semesters left before graduation or a similar kind of metric for judging the effectiveness of the system. These experiments give hope that the alert and recommender systems might help to increase the college graduation rate. Nonetheless, the design and implementation of the features will play an important role.

In the next step, more student dynamics will be included in the model. Currently, the model only considers the interaction between students and advisors. In the future, student to student interactions will be analyzed. In addition, more features of the recommendation system will be tested, and the results from the model will be validated based on the observed data.

\section{ACKNOWLEDGMENTS}

The authors would like to thank DataLab and College of Science at the George Mason University for their support in making this project possible.

\section{REFERENCES}

Baldridge, V. J., F. R. Kemerer, K. C. Green et al. 1982. "Enrollements in the eighties: factors, actors, and impacts". AAHE-ERIC/higher education research report; 3.

Bonabeau, E. 2002. "Agent-based modeling: Methods and techniques for simulating human systems". Proceedings of the national academy of sciences vol. 99 (suppl 3), pp. 7280-7287.

Business insider 2014. "Here's The Average SAT Score For Every College Major".

Cai, Y. 2013. "Graduate employability: A conceptual framework for understanding employers' perceptions". Higher Education vol. 65 (4), pp. 457-469.

Crookston, B. B. 2009. "A developmental view of academic advising as teaching". NACADA journal vol. 29 (1), pp. 78-82.

De Bakker, G., J. Van Bruggen, W. Jochems, and P. Sloep. 2011. "Introducing the SAPS system and a corresponding allocation mechanism for synchronous online reciprocal peer support activities".

Fishman, J. A., and A. K. Pasanella. 1960. "Chapter II: College Admission-Selection Studies". Review of Educational Research vol. 30 (4), pp. 298-310.

$\mathrm{Gu}, \mathrm{X}$, and K. Blackmore. 2015. "A systematic review of agent-based modelling and simulation applications in the higher education domain". Higher Education Research \& Development vol. 34 (5), pp. 883-898.

Habley, W. R. 1981. "Academic advisement: The critical link in student retention”. Naspa Journal vol. 18 (4), pp. 45-50.

Habley, W. R., and R. McClanahan. 2004. "What works in student retention". Iowa City, IA: American College Testing Service. Retrieved February vol. 21, pp. 2005.

Hezlett, S. A., N. Kuncel, M. Vey, A. Ahart, D. Ones, J. Campbell, and W. Camara. 2001. "The effectiveness of the SAT in predicting success early and late in college: A comprehensive meta-analysis". In annual meeting of the National Council on Measurement in Education, Seattle, WA.

Kelley, K. N., and M. J. Lynch. 1991. "Factors students use when evaluating advisors". NACADA Journal vol. 11 (1), pp. 26-33.

Kirk-Kuwaye, M., and D. Nishida. 2001. "Effect of low and high advisor involvement on the academic performances of probation students". NACADA journal vol. 21 (1-2), pp. 40-45. 
Kobrin, J. L., and R. S. Michel. 2006. "The SAT $®$ as a Predictor of Different Levels of College Performance. Research Report No. 2006-3.”. College Board.

Kobrin, J. L., B. F. Patterson, E. J. Shaw, K. D. Mattern, and S. M. Barbuti. 2008. "Validity of the SAT® for Predicting First-Year College Grade Point Average. Research Report No. 2008-5.". College Board.

Kot, F. C. 2014. "The impact of centralized advising on first-year academic performance and second-year enrollment behavior". Research in higher education vol. 55 (6), pp. 527-563.

Macal, C. M., and M. J. North. 2005. "Tutorial on agent-based modeling and simulation". In Proceedings of the Winter Simulation Conference, 2005., pp. 14-pp. IEEE.

Mori, K., and S. Kurahashi. 2011. "Optimising of support plans for new graduate employment market using reinforcement learning". International Journal of Computer Applications in Technology vol. 40 (4), pp. 254-264.

Murphy, K. M., and F. Welch. 1993. "Inequality and relative wages". The American Economic Review vol. 83 (2), pp. 104-109.

Murtaugh, P. A., L. D. Burns, and J. Schuster. 1999. "Predicting the retention of university students". Research in higher education vol. 40 (3), pp. 355-371.

O’Banion, T. 1994. "An academic advising model”. NaCADA Journal vol. 14 (2), pp. 10-16.

Smith, C. L., and J. M. Allen. 2006. "Essential functions of academic advising: What students want and get”. Nacada Journal vol. 26 (1), pp. 56-66.

Swecker, H. K., M. Fifolt, and L. Searby. 2013. "Academic advising and first-generation college students: A quantitative study on student retention". NACADA Journal vol. 33 (1), pp. 46-53.

Triulzi, G., R. Scholz, and A. Pyka. 2011. "R\&D and knowledge dynamics in university-industry relationships in biotech and pharmaceuticals: an agent-based model". Technical report, FZID Discussion Paper.

Winston, R. B., S. C. Ender, and T. K. Miller. 1982. Developmental approaches to academic advising. Jossey-Bass.

Winston Jr, R. B., and J. A. Sandor. 1984. "Developmental academic advising: What do students want?". NACADA journal vol. 4 (1), pp. 5-13.

Young-Jones, A. D., T. D. Burt, S. Dixon, and M. J. Hawthorne. 2013. "Academic advising: does it really impact student success?”. Quality Assurance in Education vol. 21 (1), pp. 7-19.

\section{AUTHOR BIOGRAPHIES}

AJAY KULKARNI is a Ph.D. student at George Mason University. He holds a Master of Science from the George Mason University and Master of Technology from the University of Pune, India. His research interests lie in educational data mining and learning analytics. His email address is akulkar8@gmu.edu.

MICHAEL EAGLE is an Assistant Professor in the Computational and Data Sciences Department in the College of Science, and is one of the founding members of the new Center for Adaptive Human-Machine Partnership (CAHMP.) Michael Eagle obtained his Ph.D. from North Carolina State University in 2015. He was a postdoctoral fellow in the Human-Computer Interface (HCI) Institute at Carnegie Mellon University till 2018. His research focuses on deriving understanding from complex interaction data from intelligent tutors and video games, educational game design with strong empirical studies showing their effectiveness in teaching introductory computer science, and new methods of individualized student modeling in the Genetics Cognitive Tutor. He has worked in data science at Blizzard Entertainment and Warner Bros. Interactive Entertainment (Turbine Inc.) Michael received an NSF GRFP Honorable Mention award, is a GAANN fellow, and Freeman-ASIA recipient. Michael was also the PI on an NSF EAPSI grant, in which he trav- 


\section{Kulkarni and Eagle}

eled to Japan and collaborated with Japanese researchers in educational data mining. His email address is meagle@gmu.edu. 